\title{
THE USE OF A CERVICAL DILATATION GRAPH IN THE MANAGEMENT OF PRIMIGRAVIDAE IN LABOUR
}

\author{
BY \\ WiLliam J. LeDGER \\ AND \\ WiLLIAM C. WITTING \\ The University of Michigan Medical Center, Department of Obstetrics and Gynecology, \\ Ann Arbor, Michigan 48104

\begin{abstract}
Summary
One thousand consecutive labours in primigravid patients were evaluated to show the value of the combined use of a cervical dilatation graph and a policy of active management. Intervention was required at a significantly higher rate in patients with abnormal cervical dilatation patterns. Significantly more Caesarean sections were performed in patients with abnormal cervical dilatation pattern. Early recognition of cervical dilatation problems, early intervention, and the avoidance of difficult vaginal deliveries have contributed to the good results.
\end{abstract}

USE of a cervical dilatation graph identifies patients with abnormal progress in labour and permits early corrective therapy. We have already reported experience with this graph (Ledger, 1969) and emphasized the simplicity of the method. Similar results were obtained by Friedman (1955), Schulman and Ledger (1964) and Friedman and Kroll (1971) (see Fig. 1). The use of this graph has been combined with a philosophy of aggressive obstetric intervention in the patient with poor progress in labour. To show the value of the combined use of a cervical dilatation graph and a policy of active management of labour, 1000 consecutive labours in primigravid patients from The Wayne County General Hospital Obstetrical Unit of the University of Michigan Medical Center from July, 1969, until October, 1970, have been analyzed.

\section{Materials AND Methods}

The cervical dilatation graph was used in the evaluation of all patients in labour. A fixed time for the onset of labour was determined on the basis of clinical history and recorded by the physician admitting the patient to the unit. The progress of labour was judged by plotting cervical dilatation against time. We recognized three abnormal cervical dilatation patterns: (1) Prolonged latent phase-a primigravida still in the latent phase of labour after 12 hours, (2) Slow active phase - a rate of cervical dilatation in the active phase of labour of less than $1 \mathrm{~cm}$. per hour, and (3) Arrest of active phase-no increase in cervical dilatation over a period of two hours or more in that phase.

These abnormal cervical dilatation patterns did not dictate therapy, but they indicated the need for clinical evaluation and possible intervention. The adequacy of the size of the pelvis relative to the size of the fetus and the quality of uterine activity were evaluated. In the majority of cases uterine activity was not considered satisfactory and amniotomy was performed and/or intravenous oxytocin was administered, beginning with no more than 0.5 mu. per minute. The rate of infusion was 


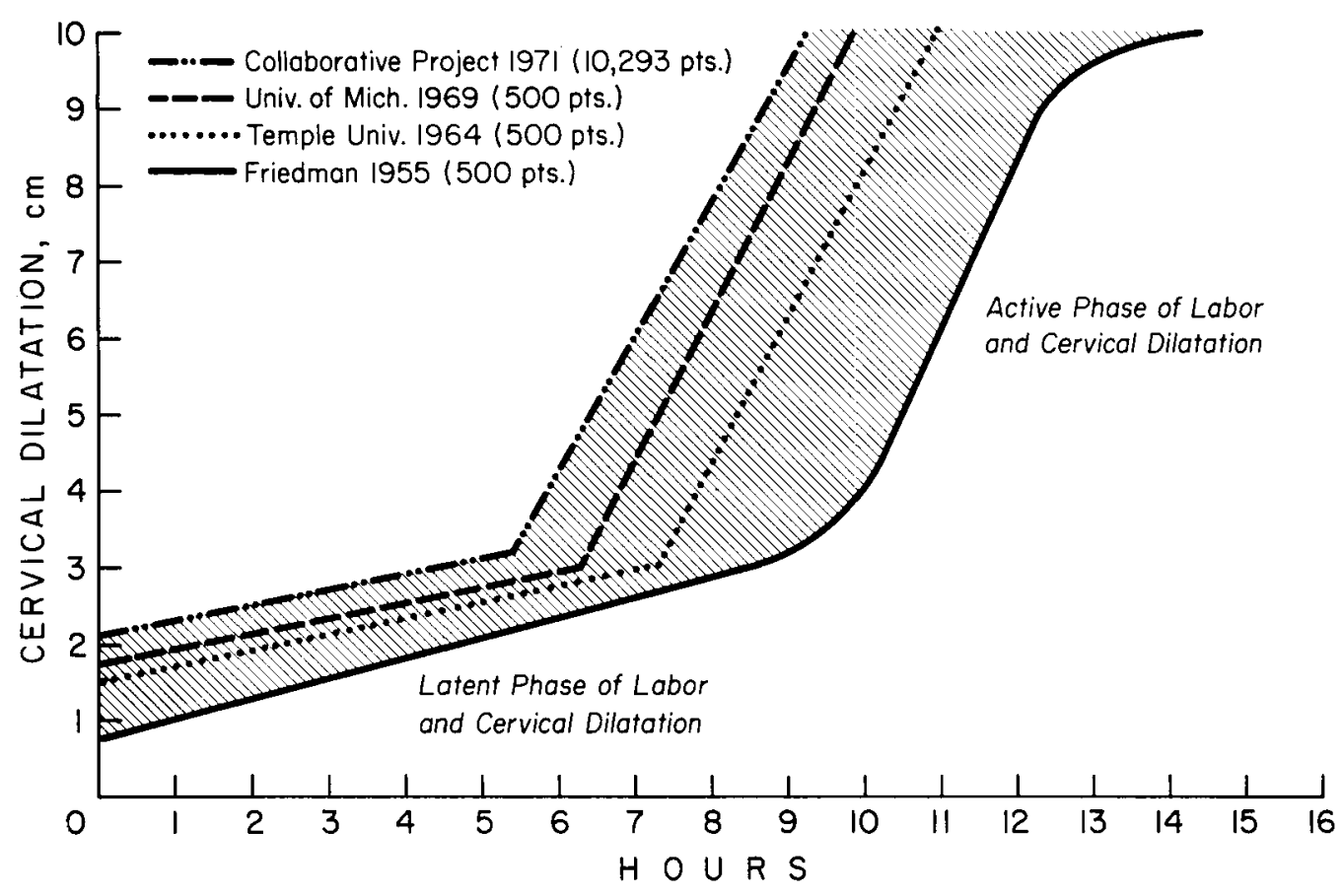

FIG. 1

A comparison of four separate analyses of primigravidae in labour. The similarity of the data is apparent.

controlled with a Harvard infusion pump. Frequently, amniotic fluid pressures and the fetal heart rate were recorded with a Corometrics FMS 101 unit. In abnormal labour sedatives were used infrequently, and were in general reserved for patients with uneffaced, undilated cervices who were suspected of not being in labour at all. In the series 38 patients were thought to be in "false labour" and were so treated.

\section{RESULTS}

The number of patients with normal and abnormal cervical dilatation patterns, and the frequency of intervention are presented in Table I. Whenever more than one abnormal pattern occurred, the last abnormal pattern of cervical dilatation was recorded in the Table.

Intervention was required in only 221 of 824 patients with normal cervical dilatation patterns but in 126 of 176 of the patients with abnormal

TABLE I

Treatment of patients

\begin{tabular}{lccccc}
\hline Pattern of labour & $\begin{array}{c}\text { No. of } \\
\text { patients }\end{array}$ & Amniotomy & Oxytocin & Both & $\begin{array}{c}\text { Total no. of } \\
\text { patients actively } \\
\text { treated }\end{array}$ \\
\cline { 3 - 5 } & & 171 & 37 & 13 & $221(27 \%)$ \\
I. Normal cervical dilatation & 824 & 35 & 49 & 42 & $126(72 \%)$ \\
II. Abnormal cervical dilatation & 176 & 15 & 21 & 16 & $52(74 \%)$ \\
Subgroups & 70 & 14 & 17 & 11 & $42(74 \%)$ \\
1. Prolonged latent phase & 57 & 6 & 11 & 15 & $32(65 \%)$ \\
2. Slow active phase & 49 & & &
\end{tabular}


patterns. This difference was statistically significant $(P<0.005)$.

A total of 46 Caesarean sections was performed ( 4.6 per cent). Only 15 of these were for the patients with normal dilatation patterns as compared to 31 for patients with abnormal dilatation patterns $(\mathrm{P}<0 \cdot 005)$. The primary indications for Caesarean section are listed in Table II. The highest incidence of Caesarean section was in patients with arrest of the active phase of dilatation ( 14 of 49 , or $28 \cdot 6$ per cent).

Twenty patients ( 2 per cent) were in labour for more than 24 hours. The most common pattern of cervical dilatation in cases of prolonged labour was a slow active phase (11 of 57).

Perinatal mortality was less in women with abnormal patterns of cervical dilatation than in those with normal patterns. The total perinatal loss was 30 per 1000 live births. There were 27 perinatal deaths in 824 deliveries with normal patterns of dilatation $(32.8$ per 1000$)$ and 3 perinatal deaths in 176 deliveries with abnormal patterns $(17.0$ per 1000). Twenty-one of the babies that died weighed less than $2500 \mathrm{~g}$. and 17 weighed less than $1500 \mathrm{~g}$. at birth.

\section{Discussion}

Use of a partograph permits early recognition of abnormalities. The limits of normality for dilatation patterns in the active phase in primigravidae are consistent and reproducible. The limits of normality for the latent phase of labour have not been as clearly defined and we have arbitrarily chosen a maximum of 12 hours in this phase as an end point, after which evaluation of the patient is essential. In a previous study (Ledger, 1969) less than 5 per cent of multiparae had a latent phase longer than 12 hours, while 15 per cent of primigravidae fell into this category. Using a limit of 12 hours for the latent phase generally insured that patients were not exhausted or dehydrated before intervention. It may be that this arbitrary time limit is too long. O'Driscoll and his colleagues have had excellent results with a policy of earlier intervention in primigravidae (O'Driscoll et al., 1970; Meagher, 1970). Our latent phase figures are much shorter than those of Friedman (1955; see Fig. 1) and we believe reflect more aggressive obstetrical management.
Table I shows a statistically significant increase in the use of amniotomy, intravenous oxytocin or both. If cephalopelvic disproportion was not found, we attempted to improve poor uterine activity no matter what the type of abnormality of cervical dilatation.

Amniotomy was valuable, particularly in the latent phase of labour (Fig. 2). A favourable clinical response to amniotomy was also noted by Alvarez et al. (1959), Cibils and Hendricks (1965) and Laros et al. (1972). If amniotomy did not improve uterine activity or if the membranes were already ruptured, low dosage oxytocin was given; improved uterine activity usually followed. Some patients with a slow active phase of labour showed a normal pattern when low dose oxytocin was given (Fig. 3).

In all, 14 per cent of this group of 1000 primigravida were given oxytocin prior to delivery, and 91 of $176(51.7$ per cent) of those with abnormal patterns of dilatation were given it. O'Driscoll et al. (1970) reported the use of oxytocin in 20 per cent of 1000 consecutive labours in primigravidae.

We do not believe that there is a place for a "therapeutic" rest for a patient in labour except for a patient with a long cervix when it is doubtful whether she is actually in labour. In

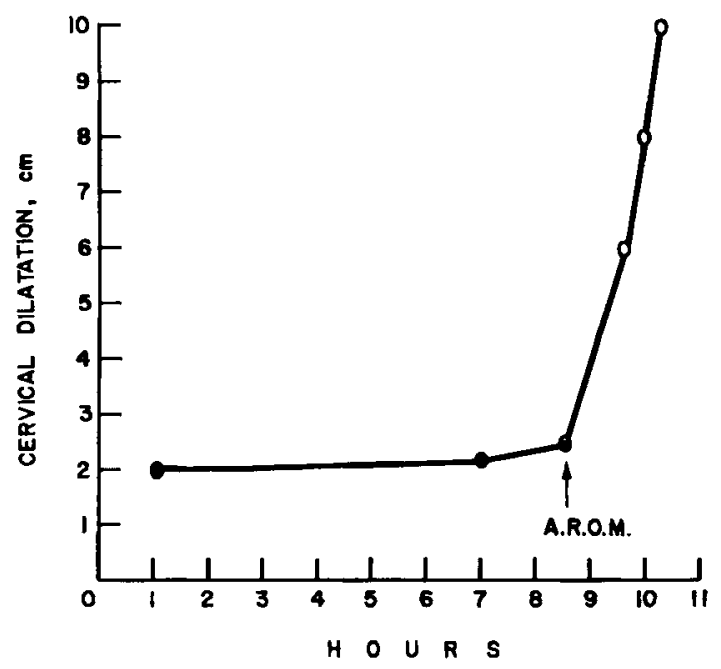

FIG. 2

Amniotomy performed in the latent phase of labour resulted in increased uterine activity and the patient rapidly entered the active phase. 


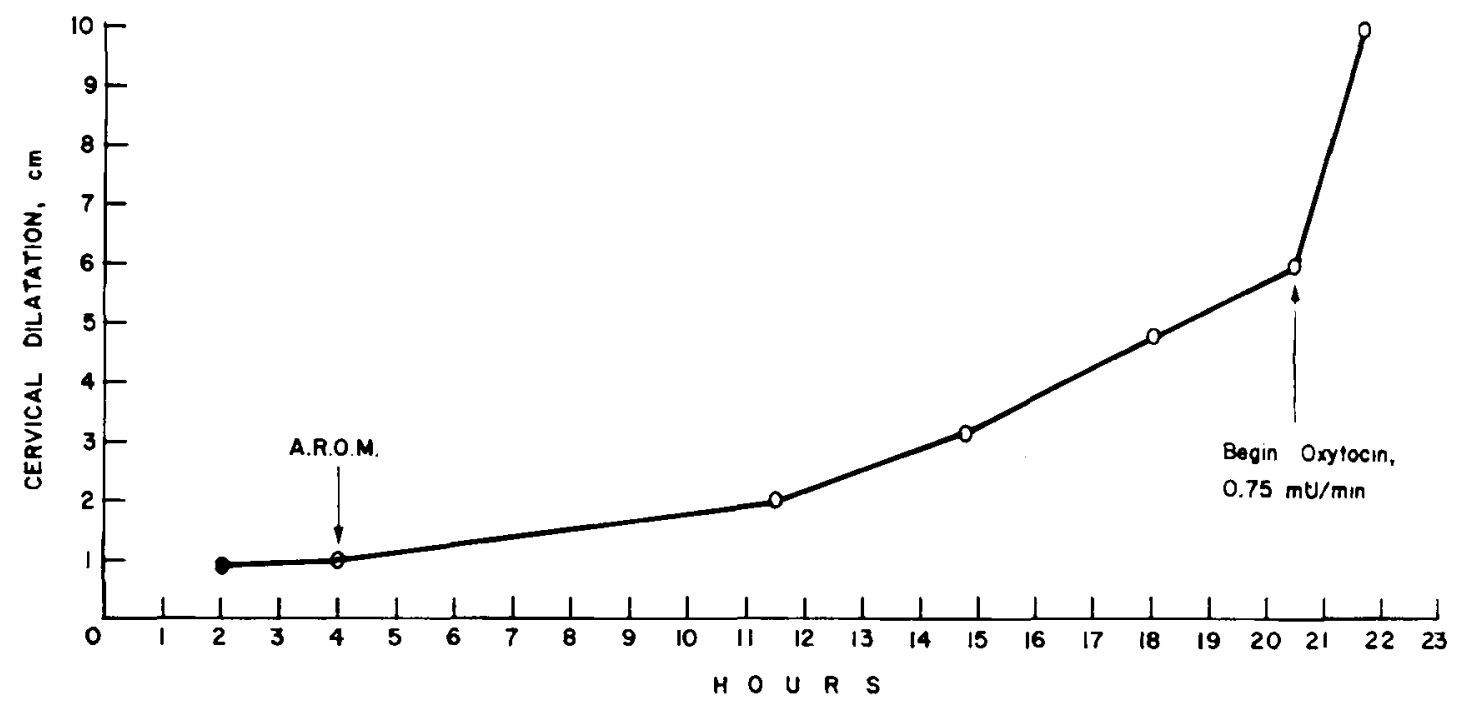

Fig. 3

Intravenous oxytocin was given to a patient with a slow active phase of labour. There was an increase in uterine activity and a normal pattern of cervical dilatation followed.

this study 38 patients were admitted to the labour floor who proved not to be in labour. Friedman (1955) suggested that sedatives should be given as the primary therapy for delay in the latent stage but our results indicate the advantages of active intervention.

The incidence and indications for Caesarean section are given in Table II. The majority of sections in patient with normal patterns of cervical dilatation were for reasons other than disproportion, while most of the sections done for patients with abnormal patterns were done for disproportion. However, only 4 of 14 Caesarean sections in patients with a prolonged latent phase were done for cephalopelvic disproportion.

In our series a diagnosis of relative disproportion in primigravidae was made far more often (24 in 1000) than in the National Maternity Hospital in Dublin (7 in 2054; Meagher, 1970). This discrepency probably reflects in part our obstetrical philosophy; the least concern about the adequacy of the pelvis dictates Caesarean section in preference to a difficult forceps

TABLE II

Indications for Caesarean section

\begin{tabular}{|c|c|c|c|c|c|c|c|c|}
\hline \multirow[b]{2}{*}{ Pattern of labour } & \multirow{2}{*}{$\begin{array}{l}\text { Total no. } \\
\text { of } \\
\text { Caesarean } \\
\text { sections }\end{array}$} & \multicolumn{7}{|c|}{ Primary indications for Caesarean section } \\
\hline & & $\begin{array}{l}\text { Cephalo- } \\
\text { pelvic } \\
\text { dispro- } \\
\text { portion }\end{array}$ & $\begin{array}{c}\text { Fetal } \\
\text { distress }\end{array}$ & Breech & $\begin{array}{c}\text { Toxae- } \\
\text { mia }\end{array}$ & $\begin{array}{c}\text { Placenta } \\
\text { praevia }\end{array}$ & $\begin{array}{c}\text { Premature } \\
\text { rupture } \\
\text { of mem- } \\
\text { branes }\end{array}$ & $\begin{array}{c}\text { Trans- } \\
\text { verse } \\
\text { lie }\end{array}$ \\
\hline $\begin{array}{l}\text { I. Normal cervical dilatation } \\
\text { II. Abnormal cervical dilatation }\end{array}$ & 15 & 4 & 6 & 2 & & 1 & & 2 \\
\hline 1. Prolonged latent phase & 14 & 4 & 1 & 3 & 4 & & 2 & \\
\hline 2. Slow active phase & 3 & 3 & & & & & & \\
\hline 3. Arrest in active phase & 14 & 13 & 1 & & & & & \\
\hline Total & 46 & 24 & 8 & 5 & 4 & 1 & 2 & 2 \\
\hline
\end{tabular}


delivery. The increased fetal mortality and morbidity of midforceps delivery has been clearly shown by Friedman and Sachtleben (1971) and Taylor (1953). Another reason for the discrepancy may be that we only use low dosage oxytocin for patients with abnormal patterns of dilatation. We have not found that patients with such patterns and disproportion commonly respond to xoytocin stimulation by developing a normal pattern.

The prospective use of the partograph has not eliminated the labour lasting longer than 24 hours; this occurred in 20 patients ( 2 per cent). Four of these had a prolonged latent phase, 5 arrest of the active phase, and 11 a slow active phase. This partly reflects our rules for recording the time of onset of labour at admission which do not permit arbitrary shortening of the recorded length of labour when progress does not proceed normally. It is probably significant that the pattern of slow active phase is most frequently associated with labour of longer than 24 hours. In some of these patients it has been impossible to accelerate progress, although others have responded to oxytocin by developing a normal pattern (Fig. 3). Our incidence of prolonged labour falls between those of Friedman and those of O'Driscoll, and probably represent a middle ground of obstetrical intervention. Friedman (1955) noted that $4 \cdot 5$ per cent of primigravidae had a latent phase of more than 20.4 hours, and the majority of these patients had a labour lasting more than 24 hours. He limited the primary use of oxytocin in labour to patients with arrest of the active phase without evidence of disproportion. At the National Maternity Hospital in Dublin (Meagher, 1970) there were only 3 among 2054 primigravidae whose labour lasted more than 24 hours; this undoubtedly was due to frequent and early use of oxytocin.

The use of a labour graph leads to early recognition of potential obstetrical problems. Our perinatal mortality of 30 per 1000 live births was largely due to low birthweight infants (21 weighed less than $2500 \mathrm{~g}$. and 17 less than $1500 \mathrm{~g}$.). In patients with abnormal patterns of cervical dilatation only 3 of 176 infants were lost, and one of these weighed less than $2500 \mathrm{~g}$.

\section{REFERENCES}

Alvarez, H., Cibils, L. A., and Gonzalez-Panizza, V. H. (1959): Oxytocin Proceedings of an International Symposium held in Montevideo. Pergamon, London. p. 203.

Cibils, L. A., and Hendricks, C. H. (1965): American Journal of 'Obstetrics and Gynecology, 91, 385.

Friedman, E. A. (1955): Obstetrics and Gynecology, 5. 567.

Friedman, E. A., and Kroll, B. H. (1971): Journal of Reproductive Medicine, 6, 63.

Friedman, E. A., and Sachtelben, M. S. (1971): Journal of Reproductive Medicine, 1, 28.

Laros, R. K., Work, B. A., and Witting, W. C. (1972): Obstetrics and Gynecology, 39, 702.

Ledger, W. J. (1969): Obstetrics and Gynecology, 34, 174.

Meagher, D. (1970): Annual Report of the National Maternity Hospital, Dublin.

O'Driscoll, K., Jackson, R. J. A., and Gallagher, J. T. (1970): Journal of Obstetrics and Gynaecology of the British Commonwealth, 77, 385.

Schulman, H., and Ledger, W. J. (1964): Obstetrics and Gynecology, 23, 442.

Taylor, E. S. (1953): Obstetrics and Gynecology 2, 302. 